\title{
Legislação e Normatização para o Glifosato no Brasil
}

\author{
Denise E. Teixeira, Renata Layse G. de Paula \& Hamilton B. Napolitano
}

Os agrotóxicos, no regime da propriedade intelectual, podem ser classificados como novas moléculas ou princípios ativos passíveis de serem patenteados. Os Tratados, Convenções e Acordos Internacionais estabelecidos entre diversos países visam à convergência de interesses de cooperação econômica para proteção às invenções. $\mathrm{O}$ glifosato é o herbicida mais vendido do mundo. A diferentes estruturas cristalinas da molécula glifosato (polimorfismo) permitiram o depósito de distintos registros de patentes. A evolução histórica do sistema internacional de patentes e da legislação interna para agrotóxicos permitem a análise dos registros do herbicida glifosato.

Palavras-chave: glifosato; polimorfismo; legistação.

The pesticides, under the regime of intellectual property, can be classified as new molecules or active principles that can be patented. The treaties, conventions and international agreements established between several countries aim at the convergence of interests of economic cooperation to protect inventions. Glyphosate is the world's best-selling herbicide. The different crystalline structures of the glyphosate molecule (polymorphism) allowed the deposit of different patent registers. The historical evolution of the international patent system and the domestic legislation for pesticides allow the analysis of the records of the glyphosate herbicide.

Keywords: glyphosete; polymorphism; legislation. 


\section{Introdução}

A utilização de produtos químicos pela sociedade global está relacionada à adoção de meios considerados essenciais ao alcance de objetivos econômicos e sociais necessários à manutenção da vida, da saúde e da propriedade. Um desses meios vem representado pela introdução dos agrotóxicos (pesticidas, inseticidas, praguicidas, biocidas, acaricidas, nematicidas, defensivos agrícolas etc.) em diversos setores econômicos. Conquanto considerado por muitos um agente poluidor capaz de degradar ecossistemas, contaminar os solos e mananciais e trazer prejuízos à saúde da população, a comunidade científica está diante do difícil papel de comprovar, de forma cabal, o nexo de causalidade entre a utilização de agrotóxicos e os malefícios à saúde humana, aos ecossistemas e à biodiversidade. ${ }^{1}$

Segundo a Lei $n^{\circ} 7.802$, de 11 de julho de 1989 (Lei dos Agrotóxicos), artigo $2^{\circ}$, alíneas "a" e "b", agrotóxicos e afins são produtos e agentes de processos fisicos, químicos ou biológicos, destinados ao uso nos setores de produção, no armazenamento e beneficiamento de produtos agrícolas, nas pastagens, na proteção de florestas, nativas ou implantadas, $e$ de outros ecossistemas e também de ambientes urbanos, hidricos e industriais, cuja finalidade seja alterar a composição da flora ou da fauna, a fim de preservá-las da ação danosa de seres vivos considerados nocivos. Incluem no conceito de agrotóxicos as substâncias e produtos empregados como desfolhantes, dessecantes, estimuladores e inibidores de crescimento.

O glifosato é o herbicida mais vendido do mundo. No Brasil, no período de 2009 a 2017, o glifosato e seus sais ficaram em $1^{\circ}$ lugar no ranking dos ingredientes ativos (de agrotóxicos) mais vendidos. O consumo nos anos de 2014 e 2015 foi superior ao dos demais anos, com cerca de 194.939,60 mil toneladas a.a.. As vendas nos anos de 2016 e 2017 foram, respectivamente, de 185.602,22 e 173.150,75 mil toneladas a.a.. Se comparado com $\mathrm{o} 2^{\circ}$ colocado no ranking de vendas, o ácido diclorofenoxiacético (2,4-D), que no período de 2014 a 2015 registrou a média de vendas de 48.750 mil toneladas a.a., o glifosato registra o consumo três vezes maior (IBAMA, 2019). ${ }^{2}$
Os agrotóxicos, no regime da propriedade intelectual, podem ser classificados como novas moléculas ou princípios ativos, passíveis de serem patenteadas garantindo o direito de exclusividade de comercialização às firmas inovadoras com parcelas mais lucrativas do mercado, e os produtos equivalentes, cujas patentes já expiraram, tornando a tecnologia de produção passível de ser explorada por empresas que não possuem capacidade de investimento em Pesquisa e Desenvolvimento (P\&D) (PELAEZ et al 2010 apud Aenda, 2007). ${ }^{3-5}$

Embora a composição química de uma molécula seja a mesma, as propriedades físico-químicas dos polimorfos que a compõem podem ser totalmente distintas, de modo a permitir o registro de patente para cada estrutura identificada. A molécula do glifosato foi pela primeira vez sintetizada em 1970, e descobertas relacionadas a suas diferentes estruturas cristalinas (polimorfismo) permitiram o depósito de distintos registros de patentes. Os Tratados, Convenções e Acordos Internacionais, estabelecidos entre diversos países, visam à convergência de interesses de cooperação econômica. A priorização de investimentos em ciência, tecnologia e inovação permite o aumento de competitividade a abertura de novos mercados. A proteção à propriedade intelectual, em especial o registro de patentes, permite a proteção privada do novo conhecimento e vantagens no comércio multilateral aos países sedes de empresas que investem em P\&D.

O Brasil tem regramento específico para o registro de patentes. O registro de novas moléculas para utilização como agrotóxicos deve observar as regras de proteção às patentes, assim como os procedimentos estabelecidos pelos órgãos federais responsáveis pela concessão de licença à produção, venda, utilização, importação e exportação de agrotóxicos. ${ }^{6-13}$ Observando a evolução histórica entre o sistema de patentes e os atos normativos desenvolvidos no Brasil para o registro de agrotóxicos, por meio de uma pesquisa exploratória e qualitativa, desenvolvida a partir do levantamento de fontes primárias (legislação) e secundárias (artigos, banco de dados de órgãos internacionais e nacionais), o presente estudo tem como objetivo explanar sobre e evolução legislativa relacionada ao registro do herbicida glifosato. 


\section{Sistema de Patentes}

Segundo Barreto ${ }^{14}$, os bens intelectuais e os produtos da mente formam o conceito de propriedade intelectual, que abrange a ideia de proteção pública para ideias, invenções e expressão criativa provenientes na maioria dos casos da atividade privada. Os Direitos da Propriedade Intelectual dividem-se em dois ramos - o Direito Autoral, que lida com criações artísticas, culturais e científicas; e o Direito da Propriedade Industrial, que se refere à proteção de patentes, desenhos industriais e marcas. Para assegurar o desenvolvimento econômico, de modo a garantir a proteção à criatividade humana e o valor comercial a bens e serviços, o Sistema Internacional de Patentes foi instituído para reger as relações comerciais de forma global.

A história do reconhecimento internacional de patentes remonta à Convention Paris (CUP) [Convenção de Paris], assinada em 20 de março de 1883, como o primeiro e mais antigo tratado em matéria de Direitos da Propriedade Intelectual. A inovação dessa Convenção foi a criação do "Princípio do Tratamento Nacional", que prevê a paridade de tratamento entre o nacional e o estrangeiro, na qual as leis que concedem ou viessem a conceder vantagens aos nacionais se estenderiam aos estrangeiros. Desde o começo, a CUP anunciou que revisões periódicas seriam realizadas, sobrevindo-se sete: em 1890, em Madri; em 1900, em Bruxelas; em 1911, em Washington D.C,; em 1925, em Haia; em 1934, em Londres; em 1958, em Lisboa e em 1967, em Estocolmo. O Brasil, país signatário original, aderiu à Revisão de Estocolmo em 1992.

Ao longo do século XX, foram celebrados diversos acordos e criadas organizações para temas afetos aos Direitos da Propriedade Intelectual. Em 1967 surgiu a World Intellectual Property Organization (WIPO) [Organização Mundial da Propriedade Intelectual OMPI], como uma das 16 agências especializadas da United Stations (UN) [Organização das Nações Unidas - ONU] dedicada à constante atualização e proposição de padrões internacionais de proteção criações intelectuais em âmbito mundial. Essa Organização, na Conferência em Washington D.C., realizada em 1970, assinou a Patent Cooperation Treaty (PCT) [Tratado de Cooperação de Matérias de Patentes], cujas modificações posteriores em 1979, 1984 e 2001 culminaram na possibilidade da proteção patentária de uma invenção, simultaneamente, em vários países, mediante a apresentação de um único pedido de patente internacional, em vez da apresentação de vários pedidos nacionais ou regionais separados.

O Strasbourg Agreement (Acordo de Estrasburgo) celebrado em 1971, estabeleceu a International Patent Classification (IPC) [Classificação Internacional de Patentes], com a definição de um sistema hierárquico de símbolos para a classificação de patentes de invenção e de modelo de utilidade de acordo com as diferentes áreas tecnológicas a que pertencem. Essa classificação é coordenada pela WIPO e foi adotada por mais de 100 países ${ }^{15}$. O Budapest Treaty (Tratado de Budapeste), firmado em 1977, estabeleceu aos países membros procedimentos e exigências para o depósito e guarda de microorganismos para fins de proteção patentária.

O General Agreement on Tariffs and Trade (GATT) [Acordo Geral sobre Tarifas e Comércio], fundado em 1947, durante a Rodada do Uruguai de Negociações Comerciais Multilaterais do GATT, ocorrida em 1994, assinou o Trade Related Intellectual Property Rigths (TRIPS) Agreement [Acordo Sobre Aspectos dos Direitos da Propriedade Intelectual Relacionados ao Comércio], que de forma ampla e detalhada harmonizou os direitos da propriedade intelectual com o comércio multilateral. Este acordo somente entrou em vigor no Brasil no ano de 2000, quando ratificado pelo País por meio do Decreto Legislativo $n^{\circ}$ 30/1994. Diário do Congresso Nacional Seção 1 - 10/08/1994, pg. 11508 (CAMARA, 2019). Ainda em 1995, após a Rodada do Uruguai, houve a fundação da World Trade Organization (WTO) [Organização Mundial do Comércio - OMC], que marcou a maior reforma do comércio internacional desde o final da Segunda Guerra Mundial. A WIPO criou em 1998 o Standing Committee on The Law Of Patents (SPC) [Comitê Permanente Sobre a Lei 
de Patentes], com o objetivo de proporcionar aos Estados membros da WIPO ou da CUP, ou até mesmo Estados que não são membros dessas organizações mas que fazem parte da ONU, além de organizações intergovernamentais e nãogovernamentais credenciadas, a oportunidade de discutir questões, facilitar a coordenação e fornecer orientações sobre o desenvolvimento progressivo internacional do direito de patentes ${ }^{16}$.

Atualmente, destacam-se como organismos de regulação e fiscalização do registro de depósitos de patentes a European Patent Office (EPO) [Organização Europeia de Patentes], criada em 1977 com base na European Patent Convention (Convenção Europeia de Patentes) de 1973, e o United States Patent and Trademark Office (USPTO) [Escritório de Patentes e Marcas dos Estados Unidos], que atua nos Estados Unidos sob regulamentação da U.S. Food \& Drug Administration (FDA).

\section{REGISTRO DE PATENTES NO BRASIL}

Como forma de assegurar o interesse social e o desenvolvimento tecnológico e econômico do Brasil, a Constituição Federal de 1988, no inciso XXIX do artigo $5^{\circ}$, prevê como direito e garantia fundamental aos autores de inventos o registro de patente, que permite a exploração de determinado bem com exclusividade. Para regulamentar este inciso, foi criada a Lei $n^{0} 9.279 / 96$, conhecida como Lei da Propriedade Industrial ${ }^{8}$.

O pedido de registro da patente no Brasil é realizado no Instituto Nacional da Propriedade Industrial (INPI), órgão do Ministério da Economia, Indústria, Comércio Exterior e Serviços que, por ato administrativo, avalia o preenchimento dos requisitos de validade e confere o título e a exclusividade de uso por um determinado tempo. Via de regra, às patentes de invenção de produtos ou processos que atendam aos requisitos de atividade inventiva, novidade e aplicação industrial, o prazo de validade concedido é de 20 anos a partir da data do depósito ${ }^{15}$.

A Instrução Normativa $n^{\circ} 18 / 2013$ INPI regulamenta o procedimento previsto nos artigos 230 e 231 da Lei 9.279/1996, permitindo às patentes depositadas no exterior a proteção no Brasil por quem tenha proteção garantida em tratado ou convenção em vigor no Brasil, ficando assegurada a data do primeiro depósito no exterior. Ainda, a Instrução Normativa $n^{\circ}$ 30/2013 do INPI (estabelecimento de normas gerais de procedimentos para explicitar e cumprir dispositivos da Lei de Propriedade Industrial, no que se refere às especificações dos pedidos de patente) estabelece normas gerais para explicar e cumprir dispositivos da Lei 9.279/1996, no que se refere às especificações dos pedidos de patente.

\section{Legislação dos Agrotóxicos}

A questão acerca da utilização de agrotóxicos no Brasil recebeu pouca atenção e quase não teve regulamentação até o final da década de 1960. A história da utilização de agrotóxicos na agricultura brasileira vem acompanhada da edição, pela Presidência da República, do Decreto ${ }^{\circ}$ 24.114, de 28 de maio de 1934, que tratou do Serviço de Defesa Vegetal, de forma a fazer referência a produtos químicos, inseticidas e fungicidas para aplicação na lavoura. Em 1969, por meio do Decreto-Lei n ${ }^{\circ}$ 917, de 7 de setembro de 1969, foi regulamentada a aviação agrícola, cuja atividade compreendia o emprego de defensivos e de fertilizantes.

A Política Nacional do Meio Ambiente (PNMA), lançada pelo Presidente João Figueiredo em 1981, por meio da Lei $n^{0} 6.938$ (dispõe sobre a Política Nacional do Meio Ambiente, seus fins e mecanismos de formulação e aplicação), não tratou do uso de agrotóxicos, que apenas foram incluídos no Anexo da PNMA pela Lei $\mathrm{n}^{\circ}$ 9.960/2000 (institui a Taxa de Serviços Administrativos, em favor da Superintendência da Zona Franca de Manaus e estabelece preços a serem cobrados pelo IBAMA), a qual trouxe a tabela de preços dos serviços e produtos cobrados pelo Instituto Brasileiro do Meio Ambiente e dos Recursos Renováveis (IBAMA) para avaliação e registro de agrotóxicos. Ao longo da década de 80, atos normativos da Divisão Nacional de Vigilância Sanitária de Saneantes Domissanitários (DISAD), como as Portarias ${ }^{\circ} 4 / 1980,5 / 1980$ e $25 / 1987$, regularam temas referentes à autorização, ao registro e à extensão de uso de 
agrotóxicos. A Portaria $\mathrm{n}^{\mathrm{o}}$ 84, de 15 de outubro de 1996, do Instituto Brasileiro do Meio Ambiente e dos Recursos Renováveis (IBAMA), estabeleceu a Classificação do Potencial de Periculosidade Ambiental (PPA) para os produtos registrados no Brasil. Essa classificação utiliza os parâmetros de bioacumulação, persistência, transporte, toxidade a diversos organismos, potencial mutagênico, teratogênico e carcinogênico, e divide-se em:

1. Produto Altamente Perigoso,

2. Produto Muito Perigoso,

3. Produto Perigoso e

4. Produto Pouco Perigoso, utilizada nos dias atuais.

O marco na legislação de agrotóxicos foi o advento da Lei $n^{\circ} 7.802$, de 11 de julho de 1989 (Lei dos Agrotóxicos). Umas das inovações trazidas foi a proibição do registro de agrotóxicos com características teratogênicas, carcinogênicas ou mutagênicas, como a determinação, a imediata avaliação aos titulares de registros de produtos que têm como componente os organoclorados a imediata avaliação. Cabe destacar que os agrotóxicos do tipo organoclorados, atualmente proibidos, foram utilizados mundialmente a partir da década de 40 como inseticidas e praguicidas. No Brasil, a Portaria $\mathrm{n}^{\circ} 329$, de 2 de setembro de 1985, proibiu a comercialização, o uso e a distribuição de agrotóxicos organoclorados destinados à agricultura. Alguns produtos como o Dicloro-Difenil-Tricloroetano (DDT) continuaram a ser permitidos como domissanitários em campanhas de saúde pública. A proibição para o uso do DDT ocorreu por meio da Lei $\mathrm{n}^{\circ} 11.936$, de 14 de maio de 2009. Também foram previstas a pesquisa, a experimentação, a produção, a embalagem e rotulagem, o transporte, o armazenamento, a comercialização, a propaganda comercial, a utilização, a importação, a exportação, o destino final dos resíduos e embalagens, o registro, a classificação, o controle, a inspeção e a fiscalização.

A Portaria n 3, 16 de janeiro de 1992, da Secretaria Nacional de Vigilância Sanitária do Ministério da Saúde, tratou de temas relacionados ao risco ocupacional e dietético, bula e rotulagem de agrotóxicos, critérios e procedimentos para avaliação e classificação toxicológica. A Lei ${ }^{0}$ 9.294, de 15 de julho de 1996, posteriormente alterada pela Lei $\mathrm{n}^{0} 10.167$, de 27 de dezembro de 2000, estabeleceu restrições ao uso e à propaganda de produtos, incluídos os defensivos agrícolas. Já a Lei $\mathrm{n}^{0}$ 9.974, de 6 de junho de 2000, trouxe maiores especificações quanto às embalagens de agrotóxicos, com destaque à obrigatoriedade de devolução das embalagens vazias aos estabelecimentos comerciais em que foram adquiridos, no prazo de até um ano da data da compra. A Política Nacional de Resíduos Sólidos, instituída pela Lei $\mathrm{n}^{0} 12.305$, de 2 de agosto de 2010, determinou aos fabricantes, importadores, distribuidores e comerciantes a obrigatoriedade de estruturar e implementar sistemas de logística reversa, mediante retorno dos produtos após o uso pelo consumidor, de forma independente do serviço público de limpeza urbana e de manejo dos resíduos sólidos, os agrotóxicos, seus resíduos e embalagens. A novidade desta Lei foi a previsão da responsabilidade civil compartilhada pelo ciclo de vida dos produtos entre o Poder Público, o setor empresarial e a coletividade.

Os órgãos federais brasileiros responsáveis pelo registro de agrotóxicos (patenteados ou genéricos) são o Ministério da Agricultura, Pecuária e Abastecimento (MAPA), a Agência Nacional de Vigilância Sanitária (ANVISA) e o Instituto Brasileiro do Meio Ambiente e dos Recursos Renováveis (IBAMA). Estes, por meio de Resoluções e Portarias, normatizam diversas situações relacionadas a critérios e exigências para avaliação e classificação toxicológica, lista de componentes, pré e pós-registros, reavaliações, licenciamento, controle, fiscalização e monitoramento de serviços, produtos e comércio.

As informações sobre o registro de patente do princípio ativo que compõem a formulação reivindicada do agrotóxico devem prestadas pelo interessado no momento da solicitação do registro do agrotóxico aos órgãos autorizadores. 


\section{Utilização de Agrotóxicos}

A utilização de produtos químicos em atividades ligadas à produção agropecuária, à indústria farmacêutica, à construção entre outros, até a primeira metade do século $\mathrm{XX}$, representou o avanço de descobertas científicas para o incremento econômico, proteção da saúde e bem-estar social. A partir da década de 60 , no entanto, começou a discussão acerca dos malefícios decorrentes da utilização de inseticidas e pesticidas pelo mundo.

Rachel Carson (1969) ${ }^{17}$, uma das precursoras do movimento ambientalista nos Estados Unidos, no discurso sobre as substâncias químicas difundidas sobre as terras de cultivo, florestas e jardins, na obra Silent Spring, alertou que, em meados da década de 40, a guerra do homem sobre a natureza, fez surgir mais de 200 substâncias para uso contra insetos, ervas daninhas, roedores e outros organismos denominados como "pestes" ou "pragas". A pulverização e a utilização de aerossóis poderiam causar a extinção da humanidade pela contaminação total do meio ambiente por substâncias que "acumulam nos tecidos das plantas e dos animais, e que até conseguem penetrar nas células germinais, a fim de estilhaçar ou alterar o próprio material em que a hereditariedade se consubstancia, e de que depende a forma do futuro". Carson afirmou "pela primeira vez na história do mundo, agora todo ser humano está sujeito ao contato com substâncias químicas perigosas, desde o instante em que é concebido até a sua morte". Em Silent Spring (Primavera Silenciosa) Rachel Carson apresenta ainda diversas situações de desastres ambientais, ocorridos nos Estados Unidos e em países europeus, causados pela utilização de inseticidas da classe dos organoclorados, em especial o DDT.

$\mathrm{Na}$ década de 70, as controvérsias sobre os possíveis danos à saúde humana e animal, aos ecossistemas e à biodiversidade envolvendo produtos químicos, culminaram na elaboração de programas para a promoção da segurança química global. O Programa United Nations Environment Programme (UNEP) [Programa das Nações Unidas para o Meio Ambiente - PNUMA], criado em 1972, pela
ONU, mobilizou diversos países para a constituição de acordos internacionais voltados ao tema. A primeira ação concreta da UNEP no campo da segurança química foi o estabelecimento, em 1976, do Registro Internacional de Substâncias Químicas Potencialmente Tóxicas (RISCPT), que teve por objetivo reunir e oferecer, por intermédio de um banco de dados, informações disponíveis sobre a produção, a distribuição e os impactos de produtos químicos ${ }^{4,18-22}$.

Em 1985, a Food and Agriculture Organization of the United Nations (FAO) criou o Código de Conduta sobre a Distribuição e Utilização de Pesticidas, que estipula consideração para a proibição de importação, distribuição, venda e compra de pesticidas altamente perigoso. Com base na avaliação de riscos, as medidas de redução desses ou as boas práticas comerciais forem consideradas insuficientes para garantir a utilização do produto sem riscos inaceitáveis para os seres humanos e o meio ambiente.

A preocupação com a promoção da segurança química global ganhou destaque a partir da Conferência das Nações Unidas sobre o Meio Ambiente e o Desenvolvimento (CNUMAD), conhecida com a Rio-92, realizada em junho de 1992 no Rio de Janeiro/Brasil, em que o plano de ação denominado Agenda 21 estabeleceu uma série de ações com vistas ao planejamento para a construção de sociedades sustentáveis. Nos Capítulos 19 e 20 desse documento, foram tratados o manejo ecologicamente saudável das substâncias químicas tóxicas e dos resíduos perigosos, incluída a prevenção ao tráfico internacional destes $^{2,13}$.

A UNEP viabilizou ainda a realização de três Convenções que trataram do manejo ambiental saudável de substâncias químicas: a Convenção de Basileia sobre o Controle de Movimentos Transfronteiriços de Resíduos Perigosos e seu Depósito (1992); a Convenção de Roterdã de Consentimento Prévio Informado (PIC) Aplicado a Certos Agrotóxicos e Substâncias Químicas Perigosas Objeto de Comércio Internacional (1998) e a Convenção de Estocolmo sobre os Poluentes Orgânicos Persistentes (1994). O Brasil é signatário destes três acordos. 


\section{Glifosato}

A molécula do glifosato [N-(fosfonometil) glicina], foi sintetizada pela primeira vez por Henri Martin em uma pequena indústria farmacêutica suíça (Cilag) no ano de 1950. Como aplicações farmacêuticas não foram identificadas, a molécula foi vendida para outras empresas e amostras foram testadas para possíveis usos finais. Atribui-se ao químico americano John E. Franz, da empresa Monsanto, o primeiro a sintetizar e testar o glifosato em 1970, que logo foi patenteado para o uso como herbicida (DUKE apud Franz et al, Grossbard e Atkinson, 2008).

A primeira patente do glifosato foi registrada nos Estados Unidos sob o $\mathrm{n}^{\circ}$ US 3799758, a qual foi seguida por numerosas outras que foram reivindicadas e obtidas pela Monsanto Company. Os herbicidas com formulações à base de glifosato, como Roundup ${ }^{\circledR}$, Accord ${ }^{\circledR}$ e Touchdown ${ }^{\circledR}$, representam os tipos mais comuns utilizados para fins agrícolas (SZÉKÁCS e DARVAS apud Franz et al, 2012). Após a expiração da proteção de patente nos Estados Unidos em 2000, as vendas de preparações genéricas expandiram-se intensamente, cujos principais produtores internacionais incluem Dow, Syngenta, NuFarm etc., mas o principal produtor de preparação permaneceu sendo a Monsanto ${ }^{18,}$ ${ }^{23}$. Recentemente a Monsanto Technology LLC realizou o pedido de patente da substância Glyphosate Salt Herbicida, em 09/11/2018 (publicado em 14/03/2019), na United States Patent and Trademarks Office (USPTO), cujo pedido tramita sob o registro ${ }^{\circ}{ }^{\text {US }} 20190075799$ A1.

Para que sejam produzidas as diversas formulações de herbicidas, é necessário conhecer a estrutura cristalina do princípio ativo para definir a concentração necessária para atingir eficácia desejada. Para um mesmo composto, podemos ter estruturas cristalinas distintas, o que caracteriza polimorfismo estrutural. Essas diferenças estruturais refletem diretamente na eficácia do produto final, visto que o polimorfismo altera as características físico-químicas do composto mudando a maneira como ele interage no meio biológico. É necessário o controle de qualidade da matéria-prima utilizada, do controle de temperatura e da umidade no meio em que é produzido o produto final e seu posterior armazenamento para que seja evitada a presença de um polimorfo e não da estrutura comercial no produto final ${ }^{24-28}$.

Para o estudo da estrutura cristalina do glifosato, foi realizada uma busca no Cambridge Crystallographic Data Centre - $(\mathrm{CCDC})^{25}$, um banco de dados de estruturas cristalinas de pequenas moléculas orgânicas com o objetivo de encontrar a estrutura cristalina do glifosato (estrutura comercial) e seus possíveis polimorfos. Por se tratar de um composto patenteado, as informações disponibilizadas para o público em geral são restritas, o que não nos permitiu gerar a imagem da estrutura cristalina do glifosado cuja patente pertence a Monsanto, mas apenas acessar alguns dados. Diante do exposto, foram localizados três estruturas polimórficas do glifosato, as quais estão descritas a seguir.

Após o lançamento do produto Roundup ${ }^{\circledR}$, muitos estudos foram realizados simultamente por diversos pesquisadores com o intuito de obter a estrutura cristalina do glifosato $\left(\mathrm{C}_{3} \mathrm{H}_{8} \mathrm{NO}_{5} \mathrm{P}\right)$. A primeira estrutura cristalina [Figura 1 - estrutura (a)] desse composto encontrada no CCDC foi apresentada pelos pesquisadores finlandeses Pekka Knuuttila e Hilkka Knuuttila em 1979, cuja amostra de glifosato utilizada foi isolada a partir do produto Roundup ${ }^{\circledR}$ e recristalizada com água quente, com o cristal obtido foi realizado a coleta de dados por meio da difração de raios $X$ para determinação da estrutura cristalina e molecular. Segundo os autores, esse trabalho visava entender o comportamento desse composto como herbicida e sua decomposição metabólica ${ }^{26}$. Posteriormente, a estrutura cristalina do glifosato $\left(\mathrm{C}_{3} \mathrm{H}_{8} \mathrm{NO}_{5} \mathrm{P}\right)$ foi publicada em 1981 pelos pesquisadores alemães Von W. Sheldrick e M.Morr [Figura 1estrutura (b)]. Nesse artigo, os autores não citam como foi obtido o cristal utilizado na difração de raios X. O objetivo desse trabalho foi contribuir no entendimento dos efeitos do glifosato como herbicida ${ }^{27}$. A estrutura 
cristalina do glifosato $\left(\mathrm{C}_{3} \mathrm{H}_{8} \mathrm{NO}_{5} \mathrm{P}\right)$ mais recente [Figura 1 - estrutura (c)], encontrada no banco de dados, foi publicada em 1993 por Henryk Krawczyk e Tadeusz J. Bartczak que obtiveram um novo poliformo através de uma nova rota sintética ${ }^{26-28}$.

A Tabela 1 apresenta alguns dados da estrutura cristalina do glifosato a qual pertence a patente registrada pela Monsanto (estrutura comercial) e seus respectivos polimorfos encontrados no CCDC. Como esperado, a fórmula química de todos os compostos é a mesma. A estrutura (a), obtida a partir do Roundup ${ }^{\circledR}$, apresenta maior semelhança com a estrutura comercial, ambas cristalizaram no mesmo grupo espacial e têm cela unitária com parâmetros geométricos próximos. A estrutura (b), como mencionado, não cita como o composto estudado foi obtido, ela também se assemelha à estrutura comercial, compartilhando o mesmo grupo espacial e tendo parâmetros geométricos da cela unitária com valores semelhantes. A estrutura (c) foi obtida a partir de um composto sintetizado a partir de uma nova rota sintética, é a que mais se distingue da estrutura comercial, tendo cristalizado em um grupo espacial distinto e evidenciando eixos menores.

$\mathrm{Na}$ Figura 1, podem-se observar as diferenças entre as estruturas polimórficas do glifosato. As estruturas (a) e (b) apresentam conformações mais similares. Contudo, é possível visualizar com facilidade as diferenças estruturais existentes entre elas. A estrutura (c) apresenta conformação bem diferente das demais.

Mesmo com o conhecimento da existência de polimorfos, não há forma totalmente eficiente de controle da estabilidade da estrutura cristalina, desde a matériaprima até o produto final, a fim de que o composto químico não sofra polimorfismo durante todo processo de produção.

Tabela 1. Dados da estrutura cristalina do glifosato e de seus polimorfos

\begin{tabular}{|c|c|c|c|}
\hline Estrutura & Fórmula química & Grupo espacial & Parâmetros geométricos da cela unitária \\
\hline Estrutura comercial & $\mathrm{C}_{3} \mathrm{H}_{8} \mathrm{NO}_{5} \mathrm{P}$ & $\mathrm{P} 21 / \mathrm{c}$ & $\begin{array}{l}\mathrm{a}=8,687(1) \AA \quad \mathrm{b}=7,989(8) \AA \quad \mathrm{c}=9,893(2) \AA \\
\alpha=90,00 \AA \quad B=105.75(1) \AA \quad y=90,00 \AA \\
\text { Volume: } 660,801 \AA^{3}\end{array}$ \\
\hline Estrutura (a) & $\mathrm{C}_{3} \mathrm{H}_{8} \mathrm{NO}_{5} \mathrm{P}$ & $\mathrm{P} 21 / \mathrm{c}$ & $\begin{array}{l}\mathrm{a}=8,682(5) \AA \quad \mathrm{b}=7,973(8) \AA \quad \mathrm{c}=9,875(5) \AA \\
\alpha=90,00 \AA \quad B=105.74(4) \AA \quad y=90,00 \AA \\
\text { Volume: } 657,931 \AA^{3}\end{array}$ \\
\hline Estrutura (b) & $\mathrm{C}_{3} \mathrm{H}_{8} \mathrm{NO}_{5} \mathrm{P}$ & $\mathrm{P} 21 / \mathrm{c}$ & $\begin{array}{l}\mathrm{a}=8,673(2) \AA \quad \mathrm{b}=7.977(3) \AA \quad \mathrm{c}=9,889(3) \AA \\
\alpha=90,00 \AA \quad B=105,67(3) \AA \quad y=90,00 \AA \\
\text { Volume: } 658,738 \AA^{3}\end{array}$ \\
\hline Estrutura (c) & $\mathrm{C}_{3} \mathrm{H}_{8} \mathrm{NO}_{5} \mathrm{P}$ & P21 & $\begin{array}{l}\mathrm{a}=7.119(<1) \AA \mathrm{b}=5,428(1) \AA \quad \mathrm{c}=9,123(<1) \AA \\
\alpha=90,00 \AA \quad B=105,04(<1) \AA \quad y=90,00 \AA \\
\text { Volume: } 340,406 \AA^{3}\end{array}$ \\
\hline
\end{tabular}




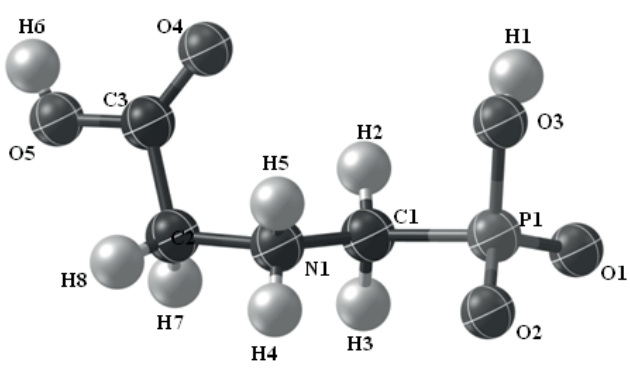

(a)

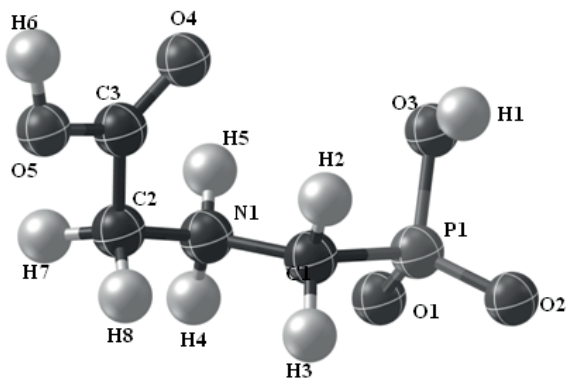

(b)

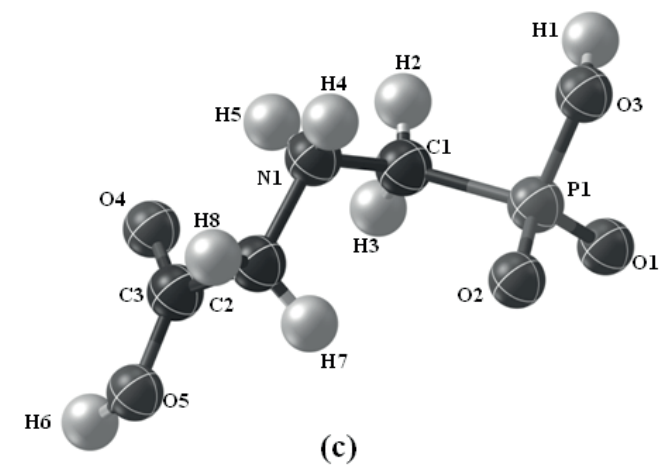

Figura 1. Estruturas cristalinas de polimorfos do glifosato

\section{Conclusão}

O sistema de patentes permite que empresas que investem em P\&D obtenham retorno financeiro devido ao monopólio da exploração econômica. Os países celebram acordos econômicos com vistas à proteção dos bens produzidos, com observância das regras de proteção à propriedade intelectual. Os países, para se adequarem aos Tratados e Acordos Internacionais, elaboram atos normativos e leis internas. Os agrotóxicos são produtos químicos amplamente utilizados pelo mundo. No Brasil, a legislação que afeta o registro, a utilização, a comercialização, a importação e a exportação, iniciou-se na década de 30 e passou por adaptações até os dias atuais. O glifosato, descoberto para aplicação na agropecuária, é o herbicida mais utilizado no Brasil e em diversos países. Suas propriedades incluem o dessecamento de pastagens e florestas.

À medida que as pesquisas e os investimentos evoluíram, a descoberta de estruturas cristalinas diversas da molécula do glifosato permitiu o registro de várias patentes. Expirado o prazo de patente das primeiras estruturas reivindicadas, surgiu a possibilidade de as indústrias agroquímicas formularem novas composições com o mesmo princípio ativo, no caso o glifosato. O princípio ativo, embora seja o mesmo, difere-se na geometria da estrutura devido ao fenômeno do polimorfismo. 
Embora o Brasil possua legislação para o registro de patentes e de agrotóxicos, evidências apontam a ausência de normas que tratam do controle de polimorfismo. O glifosato é um exemplo de um composto químico que possui patentes expiradas, as quais permitem o registro de diversos novos agrotóxicos contendo na composição essa molécula. Assim, este estudo entende a necessidade de maiores pesquisas e fiscalização sobre os novos registros de agrotóxicos concedidos pelos órgãos federais brasileiros, a fim de melhor mapeamento e previsão dos possíveis impactos socioambientais decorrentes da utilização desses produtos químicos.

\section{Referências}

1. BRASIL, Lei $\mathrm{n}^{\circ} 7.802$, de 11 de julho de 1989. Dispõe sobre a pesquisa, a experimentação, a produção, a embalagem e rotulagem, o transporte, o armazenamento, a comercialização, a propaganda comercial, a utilização, a importação, a exportação, o destino final dos resíduos e embalagens, o registro, a classificação, o controle, a inspeção e a fiscalização de agrotóxicos, seus componentes e afins, e dá outras providências. Disponível em: http://www.planalto.gov. br/ccivil_03/leis/17802.htm. Acesso em: 09.05.2019.

2. IBAMA. Instituto Nacional do Meio Ambiente e dos Recursos Naturais Renováveis. Portaria Normativa IBAMA n ${ }^{\circ} 84$, de 15 de outubro de 1996. Disponível em: http://www.ibama.gov.br/ legislacao/agrotoxicos. Acesso em: 05.04.2019.

3. Székács, András, DARVAS, Béla. 2012. Forty Years with Glyphosate, Herbicides - Properties, Synthesis and Control of Weeds, Dr. Mohammed Nagib Hasaneen (Ed.). Intechopen. DOI:10.5772/32491.

4. Vasconcelos, Rui Antônio Jucá Pinheiro de. O Brasil e o Regime Internacional de Segurança Química. 303 p. Brasília: FUNAG, 2014.

5. Palaez, V. \& Terra, F. H. B. \& Silva, L. R. A regulamentação dos agrotóxicos no Brasil: entre o poder de mercado e a defesa da saúde e do meio ambiente. Revista de Economia. v. 36, n. 1, (ano 34). p. 27-48, jan. / abr. 2010. Editora UFPR.BRASIL, Constituição da República Federativa do Brasil. Disponível em: http://www. planalto.gov.br/ccivil_03/constituicao/constituicaocompilado.htm. Acesso em: 15.08.2018.

6. BRASIL, Constituição da República Federativa do Brasil. Disponível em: http://www.planalto.gov.br/ccivil 03/constituicao/ constituicaocompilado.htm. Acesso em: 15.08.2018.

7. BRASIL, Lei ${ }^{\circ} 6.938$, de 31 de agosto de 1981. Dispõe sobre a
Política Nacional do Meio Ambiente, seus afins e mecanismos de formulação e aplicação, e dá outras providências. Disponível em: http://www.planalto.gov.br/ccivil_03/leis/16938.htm. Acesso em: 15.04.2019.

8. BRASIL, Lei $\mathrm{n}^{\circ}$ 9.279, de 14 de maio de 1996. Regula direitos e obrigações relativos à propriedade industrial. Disponível em $<$ http://www.planalto.gov.br/ccivil_03/Leis/L9279.htm> Acesso em 02.03.2019.

9. BRASIL, Lei $n^{\circ} 9.974$, de 6 de junho de 2000. Altera a Lei no 7.802, de 11 de julho de 1989, que dispõe sobre a pesquisa, a experimentação, a produção, a embalagem e rotulagem, o transporte, o armazenamento, a comercialização, a propaganda comercial, a utilização, a importação, a exportação, o destino final dos resíduos e embalagens, o registro, a classificação, o controle, a inspeção e a fiscalização de agrotóxicos, seus componentes e afins, e dá outras providências. Disponível em: http://www.planalto.gov. br/ccivil_03/Leis/L9974.htm. Acesso em: 10.04.2019.

10. BRASIL, Decreto $n^{\circ} 4.074$, de 4 de janeiro de 2002. Regulamenta a Lei no 7.802, de 11 de julho de 1989, que dispõe sobre a pesquisa, a experimentação, a produção, a embalagem e rotulagem, $o$ transporte, o armazenamento, a comercialização, a propaganda comercial, a utilização, a importação, a exportação, o destino final dos resíduos e embalagens, o registro, a classificação, o controle, a inspeção e a fiscalização de agrotóxicos, seus componentes e afins, e dá outras providências. Disponível em: http://www.planalto.gov. br/ccivil_03/decreto/2002/d4074.htm. Acesso em 15.04.2019.

11. BRASIL, Lei $\mathrm{n}^{\mathrm{o}} 11.936$, de 14 de março de 2009. Proíbe a fabricação, a importação, a exportação, a manutenção em estoque, a comercialização e o uso de diclorodifeniltricoretano (DDT) e dá outras providências. Disponível em: http://www.planalto.gov. br/ccivil 03/ Ato2007-2010/2009/Lei/L11936.htm. Acesso em: 20.05.2019.

12. BRASIL, Ministério da Saúde. Divisão Nacional de Vigilância Sanitária de Produtos Domissanitários. Portarias n ${ }^{\circ} 4,5$ e 25, de 30 de abril de 1980, 6 de maio de 1980 e de 23 de outubro de 1987. Diário Oficial da União. Brasília.

13. IBAMA. Instituto Nacional do Meio Ambiente e dos Recursos Naturais Renováveis. Relatórios de comercialização de agrotóxicos. Disponível em: http://www.ibama.gov.br/agrotoxicos/relatoriosde-comercializacao-de-agrotoxicos\#sobreosrelatorios. Acesso em: 20.04.2019.

14. Barreto, Ana Cristina Costa. Direito à Saúde e Patentes Farmacêuticas - O acesso a medicamentos como preocupação global para o desenvolvimento. Revista Aurora. Ano V, n. 7, 2011. ISSN 1982-8004.

15. INPI, Instituto Nacional da Propriedade Industrial. Diretrizes de Exame de Patentes Farmacêuticas. Rio de Janeiro, 2018. Disponível em: http://www.abifina.org.br/arquivos/download/palestra_abifina_ 
outubro_2018_flavia_trigueiro.pdf. Acesso em: 10.05.2019.

16. FPO, Free Patent Online. Driving Ip Forward. Patent 20190075799. Agbaje, Henry (Greensboro, NC, US), Eaton, David R. (Kirkwood, MO, US), Graham, Jeffrey A. (Chesterfield, MO, US), 2019. Glyphosate Salt Herbicidal Composition. United States Monsanto Technology LLC (St. Louis, MO, US).

17. Carson, Rachel. Silent Spring. Primavera Silenciosa. Desenhos de Lois e Loius Darling. Tradução de Raul de Polillo. $2^{\mathrm{a}}$ ed. Edições Melhoramentos. 1969, p. 305.

18. Duke, Stephen O. POWLES, B. Mini-review Glyphosate: a once-ina-century herbicide. Pest Managament Sience SCI v. 64: 319-325, 2008. DOI: $10.1002 /$ ps. 1518.

19. MAPA. Ministério da Agricultura, Pecuária e Abastecimento. Legislação Agrotóxicos. Disponível em: http://www.agricultura. gov.br/assuntos/insumos-agropecuarios/insumos-agricolas/ agrotoxicos/legislacao. Acesso em: 17.03.2019.

20. MMA. Ministério do Meio Ambiente. Agenda 21 Global. Disponível em: http://www.mma.gov.br/responsabilidade-socioambiental/ agenda-21/agenda-21-global. Acesso em: 14.05.2019.

21. ONU, Organização das Nações Unidas - Brasil. A ONU e o Meio Ambiente. Disponível em: https://nacoesunidas.org/acao/meioambiente/. Acesso em: 29.04.2019.

22. USPTO. United States Patent and Trademark Office. Patent US 3799758. N-Phosphonomethyl-Glycine Phytotoxicant Compositions. John E. Franz, Crestwood, Mo., assignor to Monsanto Company. USPTO. United States Patent and Trademark Office.

23. BAYER. Bayer Brasil. Produtos de A a Z. Disponível em: https:// www.bayer.com/en/products-from-a-to-Z.aspx. Acesso em: 31.03.2019.

24. Lariucci, Carlito e NAPOLITANO, Hamilton B. e CUNHA, Silvio. Inovação Tecnológica e Polimorfismo de Fármacos. Revista Processos Químicos, v. 2, p. 59-65, 2008.

25. Groom, Colin R. et al. The Cambridge Structural Database. Acta Crystallographica Section B Structural Science, Crystal Engineering and Materials, v. 72, n. 2, p. 171-179, 1 Apr. 2016. Disponível em: <http://scripts.iucr.org/cgi-bin/ paper?S2052520616003954>.

26. Knuuttila, Pekka e KNUUTTILA, Hilkka. The Crystal and Molecular Structure of N-(Phosphonomethyl)glycine (Glyphosate). Acta Chemica Scandinavica, v. 33b, p. 623-626, 1979. Disponível em: $<$ http://actachemscand.org/doi/10.3891/acta.chem. scand.33b-0623>.

27. Sheldrick, W. S. e MORR, M. N -Phosphonomethylglycin. Acta Crystallographica Section B Structural Crystallography and Crystal Chemistry, v. 37, n. 3, p. 733-734, 1 Mar. 1981. Disponível em: $<$ http://scripts.iucr.org/cgi-bin/paper?S0567740881004111>.
28. Krawczyk, Henryk e BARTCZAK, Tadeusz J. New Crystalline Polymorphic Form of Glyfosate: Synthesis, Crystal and Molecular Structures of N -(Phosphonomethyl)glycine. Phosphorus, Sulfur, and Silicon and the Related Elements, v. 82, n. 1-4, p. 117-125, Feb. 1993. Disponível em: <http://www.tandfonline.com/doi/ abs/10.1080/10426509308047415>.

\section{Denise E. Teixeira ${ }^{1,2}$, Renata Layse G. de Paula ${ }^{3}$ e Hamilton B. Napolitano ${ }^{1,3}$}

\author{
${ }^{1}$ Programa de Pós-Graduação em Sociedade, \\ Tecnologia e Meio Ambiente (PPGSTMA) da \\ UniEVANGÉLICA, Av. Universitária, km 3,5, Cidade \\ Universitária, CEP 75083-515, Anápolis GO. \\ ${ }^{2}$ Tribunal de Justiça do Estado de Goiás. Goiânia, GO. \\ ${ }^{3}$ Universiade Estadual de Goias, Anápolis, GO. Grupo \\ de Química Teórica e Estrutural de Anápolis.
}

\section{*E-mail: denise_det@hotmail.com}


